\title{
Consumo e desempenho produtivo de ovinos alimentados com dietas que continham coprodutos do desfibramento do sisal
}

[Intake and productive performance of sheep fed sisal coproducts based diets]

\author{
R.D. Santos ${ }^{1}$, L.G.R. Pereira ${ }^{2}$, A.L.A. Neves ${ }^{2}$, L.G.N. Brandão ${ }^{3}$, G.G.L. Araújo ${ }^{1}$, \\ A.S.L. Aragão $o^{4}$, W.N. Brandão ${ }^{1}$, R.A. Souza ${ }^{5}$, G.F. Oliveira ${ }^{6}$ \\ ${ }^{1}$ Embrapa Semiárido - BR 428, KM 152, Zona Rural, \\ Caixa Postal 23 \\ 56300-970 - Petrolina, PE \\ ${ }^{2}$ Embrapa Gado de Leite - Juiz de Fora, MG \\ ${ }^{3}$ FTC - Feira de Santana, BA \\ ${ }^{4}$ Aluno de pós-graduação - UFMG - Belo Horizonte, MG \\ ${ }^{5}$ Aluno de pós-graduação - UNIVASF - Petrolina, PE \\ ${ }^{6}$ Bolsista Embrapa Semiárido - Petrolina, PE
}

\begin{abstract}
RESUMO
Avaliaram-se o desempenho produtivo e o consumo de nutrientes e frações fibrosas em ovinos alimentados com dietas contendo coprodutos do desfibramento do sisal, Agave sisalana. Foram utilizados 24 ovinos, machos, alojados em baias individuais. O delineamento experimental utilizado foi o inteiramente ao acaso, com quatro tratamentos e seis repetições. Os tratamentos consistiram em quatro dietas isoproteicas, em que: i) dieta padrão, contendo $38 \%$ de volumoso (silagem de milheto) e $62 \%$ de concentrado (milho, farelo de soja e ureia); ii) inclusão de $20 \%$ da silagem de mucilagem do sisal em substituição à silagem de milheto; iii) inclusão de $20 \%$ da silagem de mucilagem associada ao pó da batedeira como aditivo em substituição à silagem de milheto; $i v$ ) inclusão de $20 \%$ do feno da mucilagem em substituição à silagem de milheto. O peso corporal final, os ganhos médio diário e total e a conversão alimentar dos ovinos não foram influenciados pelas dietas avaliadas $(\mathrm{P}>0,05)$. Os consumos dos nutrientes, em $\mathrm{g} / \mathrm{dia}$ e em $\% \mathrm{PC}$ e $\mathrm{g} / \mathrm{kg}^{0,75}$, não sofreram influência das dietas. Os resultados indicam que as dietas à base de coprodutos do sisal podem ser utilizadas como alternativa volumosa, além de possibilitar o aumento da rentabilidade da atividade na região semiárida brasileira.
\end{abstract}

Palavras-chave: ovino, Agave sisalana, ganho de peso, nutrientes, resíduo agroindustrial, subproduto

\begin{abstract}
The objective of this study was to evaluate the productive performanceand mean daily intake of nutrients in sheep fed diets containing sisal, Agave sisalana, and co-products. Twenty-four male sheep were used in individual stalls. A completely randomized design was used, with four treatments and six replications. The treatments consisted of four isonitrogenous, in which: i) standard diet containing $38 \%$ forage (millet silage) and $62 \%$ concentrate (corn, soybean meal and urea), ii) inclusion $20 \%$ agave mucilage silage to replace millet silage in the standard diet, iii) inclusion of $20 \%$ agave mucilage silage associated with agave powder as additive to replace millet silage in the standard diet, iv) inclusion of $20 \%$ agave mucilage hay in substitution of millet silage. The final body weight, average daily gain, the total weight gain and feed conversion of sheep was not affected by the diets tested (P>0.05). Similarly, the intake of nutrients in $\mathrm{g} / \mathrm{day}, \% \mathrm{BW}$ and $\mathrm{g} / \mathrm{kg}^{0,75}$ were not affected by the diets. The results indicate that the experimental diets based on the agave co-products can be used as alternative roughage in the semiarid region of Brazil, as well as help increase the profitability of cattle ranching in the region.
\end{abstract}

Keywords: sheep, Agave sisalana, weight gain, nutrients, agriculture waste, by-product

Recebido em 22 de abril de 2010

Aceito em 12 de julho de 2011

E-mail: rafael.dantas@cpatsa.embrapa.br 


\section{INTRODUÇÃO}

Os sistemas de criação de caprinos e ovinos nas regiões semiáridas do Brasil fundamentam-se na exploração extensiva, com baixo nível de tecnologia e com forte dependência da vegetação nativa conhecida como caatinga, sendo esta muitas vezes a única fonte de alimentação volumosa. Esses fatores estão associados ao baixo desempenho produtivo e econômico dos rebanhos nordestinos. A estacionalidade produtiva de forragens de boa qualidade, assim como a necessidade de atender a produção de ruminantes no Nordeste brasileiro, impulsiona os produtores do semiárido a buscarem alternativas alimentares para os seus rebanhos. O aproveitamento de coprodutos agroindustriais pode ser uma opção de suplementação alimentar.

No Brasil, o estado da Bahia é o principal produtor de sisal (Agave sisalana, Perrine), com produção anual de fibra equivalente a 234.847 toneladas (Censo..., 2007). Desse modo, estimase que sejam gerados mais de 5 milhões de toneladas por ano de coprodutos (resíduos) do sisal, e que apenas $4 \%$ das folhas do sisal são aproveitadas na forma de fibras. Esse coproduto é utilizado como adubo orgânico ou como alimento para animais. Sem conhecimento do valor nutritivo e sobre as melhores formas de fornecimento e armazenamento do coprodutos do sisal, os produtores têm utilizado o coproduto de forma empírica, já que não existem resultados, embasados cientificamente, acerca da utilização destes coprodutos nas suas mais diversas apresentações, em condições semiáridas brasileiras.

O resíduo do sisal tem grande potencial para ser transformado em coproduto e constituir alimento estratégico para a pecuária, no entanto são necessários estudos que esclareçam as melhores formas de armazenamento e fornecimento, assim como avaliações sobre a composição bromatológica e ensaios de consumo e desempenho com animais alimentados com coprodutos do sisal.

O objetivo deste trabalho foi avaliar o desempenho bioeconômico e consumo de nutrientes em ovinos alimentados com dietas que continham coprodutos do desfibramento do sisal.

\section{MATERIAL E MÉTODOS}

O experimento foi realizado no Instituto de Desenvolvimento da Região do Sisal - IDR Sisal, em Valente-BA, e o delineamento experimental utilizado foi inteiramente ao acaso, com quatro tratamentos e seis repetições.

Os tratamentos consistiram em quatro dietas isoproteicas contendo $15 \%$ de proteína bruta, em que: $i$ ) dieta-padrão, contendo $38 \%$ de volumoso (silagem de milheto) e $62 \%$ de concentrado (milho moído fino, farelo de soja e ureia); ii) inclusão de $20 \%$ da silagem de mucilagem do sisal em substituição à silagem de milheto na dieta-padrão; iii) inclusão de $20 \%$ da silagem de mucilagem associada ao pó da batedeira como aditivo, sendo $95 \%$ de mucilagem e $5 \%$ de pó de batedeira, em substituição à silagem de milheto na dieta-padrão; $i v$ ) inclusão de $20 \%$ do feno da mucilagem em substituição à silagem de milheto (Tab. 1 e 2).

As dietas foram formuladas de modo que as dietas atendessem as recomendações de proteína bruta (PB) e energia metabolizável (EM) preconizadas pelo NRC (Nutrient..., 2007), para ganho médio de peso diário de $200 \mathrm{~g}$.

A silagem de milheto foi utilizada como volumoso padrão nas dietas experimentais. A escolha desta opção foi baseada no fato de ser uma cultura adaptada às condições semiáridas e pelo comprovado potencial de conservação da forragem de milheto na forma de silagem (Guimarães Jr. et al., 2008), alimento úmido e estratégico para os rebanhos nordestinos criados em condições semiáridas. A semeadura, colheita e ensilagem do milheto em tonéis plásticos (capacidade para $200 \mathrm{~kg}$ ) foram realizadas na Embrapa Semiárido, em Petrolina-PE. As plantas foram colhidas quando apresentavam aproximadamente 100 dias de crescimento e os grãos em estádio farináceo, sendo cortadas rente ao solo, amontoadas e picadas em ensiladeira estacionária, ajustada para corte de partículas de aproximadamente $1-2 \mathrm{~cm}$. 
Tabela 1. Composição químico-bromatológica dos ingredientes das dietas experimentais

\begin{tabular}{lcccccc} 
& \multicolumn{5}{c}{ Ingrediente $(\%$ da matéria seca) } \\
\cline { 2 - 7 } Nutriente $^{1}$ & Milho & Farelo de soja & $\begin{array}{c}\text { Silagem de } \\
\text { milheto }\end{array}$ & $\begin{array}{c}\text { Silagem de } \\
\text { mucilagem }\end{array}$ & $\begin{array}{c}\text { Silagem de } \\
\text { mucilagem + } \\
\text { pó }\end{array}$ & $\begin{array}{c}\text { Feno de } \\
\text { mucilagem }\end{array}$ \\
\hline MS & 90,0 & 91,0 & 28,0 & 17,0 & 15,8 & 78,0 \\
MO & 98,4 & 92,8 & 90,4 & 82,8 & 81,1 & 83,8 \\
PB & 9,0 & 45,2 & 10,3 & 7,5 & 7,0 & 6,3 \\
FDN & 22,9 & 14,7 & 63,6 & 37,0 & 41,0 & 31,9 \\
FDA & 4,9 & 9,9 & 36,6 & 29,7 & 31,6 & 22,8 \\
CHO & 84,6 & 46,1 & 77,2 & 71,9 & 71,2 & 75,0 \\
CNF & 61,7 & 31,5 & 13,6 & 34,9 & 30,2 & 43,0 \\
EE & 4,74 & 1,7 & 2,8 & 3,3 & 2,8 & 2,5 \\
DIVMS & 84,8 & 89,9 & 53,5 & 65,5 & 69,2 & 73,4 \\
\hline
\end{tabular}

${ }^{1} \mathrm{MS}$ - matéria seca (\%); MO - matéria orgânica (\%); PB - proteína bruta (\% da MS); FDN - fibra em detergente neutro (\% da MS); FDA - fibra em detergente ácido (\% da MS); CHO - carboidratos totais (\% da MS); CNF carboidratos não fibrosos (\% da MS); EE - extrato etéreo (\% da MS); DIVMS - digestibilidade in vitro da matéria seca.

Tabela 2. Composição percentual das dietas experimentais (\% da matéria seca)

\begin{tabular}{lcccc} 
& \multicolumn{4}{c}{ Dieta } \\
\cline { 2 - 5 } Ingrediente & $\begin{array}{c}\text { Silagem de } \\
\text { milheto }\end{array}$ & $\begin{array}{c}\text { Silagem de } \\
\text { mucilagem }\end{array}$ & $\begin{array}{c}\text { Silagem de } \\
\text { mucilagem + pó }\end{array}$ & $\begin{array}{c}\text { Feno de } \\
\text { mucilagem }\end{array}$ \\
\hline Milho & 47,0 & 47,0 & 47,0 & 47,0 \\
Farelo de soja & 14,0 & 14,0 & 14,0 & 14,0 \\
Silagem de milheto & 38,8 & 20,0 & 20,0 & 20,0 \\
Silagem de mucilagem & 0,0 & 18,6 & 0,0 & 0,0 \\
Silagem de mucilagem + pó & 0,0 & 0,0 & 18,6 & 0,0 \\
Feno de mucilagem & 0,0 & 0,0 & 0,0 & 18,5 \\
Ureia & 0,20 & 0,40 & 0,40 & 0,50 \\
\hline
\end{tabular}

Utilizou-se o coproduto do desfibramento das folhas de sisal (mucilagem de sisal), processado em máquina "Paraibana", que é de fabricação artesanal, construída em madeira. O desfibramento consiste na eliminação da polpa das fibras mediante a raspagem mecânica da folha por rotores raspadores acionados por motor a diesel. Esta máquina desintegra toda a folha, exceto a sua porção fibrosa central (extremamente lignificada), que constitui a parte comercial da Agave sisalana. Após este processo, o coproduto foi peneirado em peneira rotativa manual (Silva et al., 1998), para retirada do excesso de fibras. A mucilagem foi ensilada em tonéis plásticos com capacidade para 200 litros, o mesmo ocorrendo para a mucilagem acrescida do pó de batedeira.

O pó da batedeira, coproduto obtido da varredura dos galpões de armazenamento e processamento da fibra de sisal ("batedeiras"), foi adquirido nas fazendas da região, que dispunham deste material. Para produzir o feno, o coproduto do desfibramento do sisal foi exposto ao sol por 16 horas, sendo revirado a cada duas horas e protegido por lona de polietileno durante $\mathrm{o}$ período da noite. Todos os coprodutos do sisal, que serviram como ingredientes das dietas experimentais, foram adquiridos junto aos produtores rurais da região, tendo os seus custos computados para o embasamento da análise econômica.

Utilizaram-se 24 carneiros, castrados, sem raça definida, com média de peso vivo de $27 \mathrm{~kg}$. Os animais foram mantidos em baias individuais de $2 \mathrm{~m}^{2}$, providas de bebedouros e comedouros individuais, por 78 dias (15 dias de adaptação e 63 dias para coleta de dados experimentais).

Ao início do experimento, os animais foram vermifugados, pesados, identificados com brincos numerados e sorteados entre as dietas. As pesagens foram realizadas a cada 21 dias, do início do experimento até o seu término. Para todas as pesagens do experimento, os animais foram submetidos a jejum de líquidos e sólidos por 14 horas. 
O arraçoamento ocorreu de forma a se obter $15 \%$ de sobras em relação à quantidade de ração fornecida diariamente, sendo que, juntamente com as dietas avaliadas, que foram ofertadas duas vezes ao dia ( $7 \mathrm{~h} 30 \mathrm{~min}$ e $16 \mathrm{~h} 30 \mathrm{~min}$ ), os animais receberam água e mistura mineral à vontade.

Durante o período experimental, foi quantificado o alimento fornecido e as sobras no cocho, sendo também realizadas amostragens diárias destes materiais. Do material oferecido, coletaram-se aproximadamente $300 \mathrm{~g}$ da dieta testada por dia. As sobras foram recolhidas pela manhã, pesadas e acondicionadas em sacos plásticos, identificadas e congeladas para análises posteriores, sendo geradas amostras compostas por animal.

As amostras foram pré-secas em estufa de ventilação forçada a $60^{\circ} \mathrm{C}$, durante 72 horas, e, em seguida, trituradas em moinho tipo Willey, utilizando-se peneiras dotadas de crivos de $1 \mathrm{~mm}$.

Foram determinados nas amostras de fornecido e sobras dos alimentos os teores de matéria seca
(MS), matéria orgânica (MO), proteína bruta (PB) e extrato etéreo (EE), conforme as metodologias descritas por Silva e Queiroz (2002), e fibra em detergente neutro (FDN) e fibra em detergente ácido (FDA), segundo Van Soest et al. (1991). Os teores de carboidratos totais $(\mathrm{CHO})$ e carboidratos não fibrosos (CNF) foram obtidos pelas equações: $\mathrm{CHO}=100-$ $(\mathrm{PB} \%+\mathrm{EE} \%+\mathrm{MM} \%)$ e $\mathrm{CNF}=100-(\mathrm{PB} \%+$ $\mathrm{EE} \%+\mathrm{MM} \%+\mathrm{FDN} \%)$, de acordo com Sniffen et al. (1992), e digestibilidade in vitro da matéria seca (DIVMS), conforme o método das duas etapas (Tilley e Terry, 1963). Os resultados são apresentados na Tab. 3. As porcentagens de inclusão dos coprodutos do sisal das dietas foram limitadas devido à necessidade de não ultrapassar o nível máximo de $40 \%$ de CNF e mínimo de $30 \%$ de FDN de acordo com as recomendações de Kozloski et al. (2006) para dietas de borregos em confinamento.

Para o cálculo da conversão alimentar, considerou-se a relação entre o consumo de MS e o ganho médio diário $(\mathrm{kg}$ de matéria seca consumida por ovino por dia/kg de PV ganho por ovino por dia).

Tabela 3. Composição nutricional das dietas experimentais

\begin{tabular}{lcccc} 
Ingrediente $(\%)^{\mathbf{1}}$ & \multicolumn{4}{c}{ Dieta } \\
\cline { 2 - 5 } & $\begin{array}{c}\text { Silagem de } \\
\text { milheto }\end{array}$ & $\begin{array}{c}\text { Silagem de } \\
\text { mucilagem }\end{array}$ & $\begin{array}{c}\text { Silagem de } \\
\text { mucilagem + pó }\end{array}$ & $\begin{array}{c}\text { Feno de } \\
\text { mucilagem }\end{array}$ \\
\hline MS & 48,4 & 40,0 & 38,7 & 60,9 \\
MO & 94,5 & 93,1 & 92,8 & 93,3 \\
PB & 15,0 & 15,0 & 15,0 & 15,0 \\
FDN & 37,5 & 32,4 & 33,1 & 31,4 \\
FDA & 17,9 & 16,5 & 16,9 & 15,2 \\
CHO & 75,9 & 75,1 & 74,9 & 75,6 \\
CNF & 38,4 & 42,6 & 41,7 & 44,1 \\
EE & 3,5 & 3,6 & 3,5 & 3,5 \\
DIVMS & 73,2 & 75,3 & 76,0 & 76,7
\end{tabular}

${ }^{1} \mathrm{MS}$ - matéria seca (\%); MO - matéria orgânica (\%); PB - proteína bruta (\% da MS); FDN - fibra em detergente neutro (\% da MS); FDA - fibra em detergente ácido (\% da MS); CHO - carboidratos totais (\% da MS); CNF carboidratos não fibrosos (\% da MS); EE - extrato etéreo (\% da MS); DIVMS - digestibilidade in vitro da matéria seca.

As variáveis foram testadas para verificar a ocorrência de distribuição normal antes de se proceder à análise de variância. Como foi identificado que os dados obtidos seguiam a distribuição normal, eles foram submetidos à análise de variância. Posteriormente, as médias foram comparadas pelo teste de Tukey a $5 \%$ de probabilidade $(\mathrm{P}<0,05)$, por intermédio do software SAS (Statistical..., 2002).
Foi realizada análise econômica em relação ao ganho de peso diário, a fim de se verificar a viabilidade de utilização do coproduto do sisal de três diferentes formas, sem considerar os demais custos fixos e operacionais relativos à produção ovina, como mão de obra, tempo de preparo e equipamentos utilizados, pois estes custos foram os mesmos para cinco situações. Para os cálculos que fundamentaram a análise econômica, 
tomaram-se como base o ganho de peso total no período de confinamento, o preço por quilograma de carne praticado na região, o consumo total de matéria seca e o preço por quilograma da matéria seca.

\section{RESULTADOS E DISCUSSÃO}

Os valores observados para a composição bromatológica dos coprodutos de sisal utilizados nas dietas são compatíveis com os dados médios citados por Valadares Filho et al. (2006) na Tabela Brasileira de Composição de Alimentos, onde foram reportados os valores de 18,9\%, $87,1 \%, 9,4 \%$ e $2,5 \%$ para MS, MO, PB e EE, respectivamente.

Os teores de matéria seca obtidos foram semelhantes aos relatados por Gebremariam e Machin (2008), entretanto, mais altos que os obtidos por Negesse et al. (2009) e PinosRodríguez et al. (2009), ao avaliarem coprodutos de agave. Rodriguez et al. (1985) observaram valores de 19,9\% de MS e 5,8\% de PB, quando avaliaram silagem de coprodutos de sisal, no México. Os valores de PB deste ensaio foram mais elevados que os obtidos por PinosRodríguez et al. (2009), que relataram variação de 4,3 a $3,5 \%$ para a PB e de 43,6 a $46,4 \%$ de FDN para a silagem de coprodutos de sisal. Já Negesse et al. (2009) observaram valores de 33,6 e 26,9\% para FDN e FDA, respectivamente.

Não houve efeito $(\mathrm{P}>0,05)$ da inserção de coprodutos de sisal sobre o consumo de matéria seca (Tab. 4). O consumo dos demais nutrientes (MO, PB, CHO, CNF, EE) e das frações fibrosas (FDN e FDA), em g/dia, \%PC e $\mathrm{g} / \mathrm{kg}^{0,75}$, também não foi influenciado pelo acréscimo dos coprodutos (P>0,05) (Tab. 4). Esse comportamento, provavelmente, deve-se à ausência de efeito no consumo de matéria seca e à semelhança na composição nutricional das dietas.

Diversos fatores atuam no controle ou na inibição do consumo de matéria seca, que pode ser limitado pelo alimento, pelo animal ou pelas condições de alimentação (Mertens, 1997; Forbes, 1996). Entre os fatores inerentes ao alimento, destacam-se a quantidade e o tamanho da partícula; em relação à físiologia animal, destacam-se o sexo, a idade e a composição corporal. Há ainda as condições ambientais, como temperatura, vento e umidade. Allen (2000) relatou que o teor de FDN é o melhor componente na avaliação da ingestão de matéria seca pelos ruminantes e que a proporção de fibra indigestível da dieta pode alterar o consumo de matéria seca, assim como a quantidade de CNF.

Gebremariam e Machin (2008), ao estudarem a inserção de diferentes níveis de coprodutos de sisal na alimentação de ovinos na Eritreia, observaram consumo de MS de 853 a 979g/animal/dia. Pinos-Rodríguez et al. (2009) observaram consumos médios de MS, MO, PB e FDN de 680,0, 607,0, 69,5 e 178,5g/dia, respectivamente, em dietas que continham silagem de coproduto de agave.

O consumo médio de proteína bruta em g/dia obtido neste ensaio foi de 149,3g/dia, atendendo ao recomendado pelo NRC (Nutrient..., 2007), que estabelece exigência mínima de $141 \mathrm{~g} / \mathrm{dia}$ para animais em terminação, com essa faixa de peso e ganhos de $150 \mathrm{~g} /$ dia. Os consumos de nutrientes e de frações fibrosas, em porcentagem do peso corporal, foram semelhantes $(\mathrm{P}>0,05)$. A média de $2,7 \%$ PC para o consumo de matéria seca foi inferior ao encontrado por Gebremariam e Machin (2008), que verificaram variação de 3,54 a $3,74 \%$ PC, quando avaliaram ovinos alimentados com coprodutos de sisal na África subsaariana. No entanto, Herrera et al. (1981) observaram consumo de $2,4 \%$ PC para animais alimentados com silagem do coproduto de sisal.

O consumo de FDN está de acordo com o proposto por Van Soest (1994), entre 0,8 e 1,2\% $\mathrm{PC}$, demonstrando que os animais ingeriram volume satisfatório de alimentos para suprir suas necessidades nutricionais.

Não foram observadas diferenças $(\mathrm{P}>0,05)$ entre as dietas quanto ao consumo de nutrientes e frações fibrosas em $\mathrm{g} / \mathrm{kg}^{0,75}$. Os valores médios de consumo para MS, FDN e FDA foram de 67,8 $\mathrm{g} / \mathrm{kg}^{0,75} / \mathrm{dia}, 21,4 \mathrm{~g} / \mathrm{kg}^{0,75} / \mathrm{dia}$ e $11,0 \mathrm{~g} / \mathrm{kg}^{0,75} / \mathrm{dia}$, respectivamente. A mensuração do consumo das frações fibrosas é relevante, pois a fibra pode exercer vários efeitos metabólicos e fisiológicos no organismo animal. O aumento dos teores dessa fração pode provocar diluição da energia da dieta, levando ao aumento compensatório no consumo, para que os níveis energéticos exigidos para desenvolvimento e produção sejam atingidos (Van Soest et al., 1991). 
Consumo e desempenho...

Tabela 4. Consumo dos principais nutrientes e frações fibrosas de ovinos alimentados com coprodutos do desfibramento do sisal

\begin{tabular}{|c|c|c|c|c|c|c|}
\hline \multirow[b]{2}{*}{ Item $^{1}$} & \multicolumn{4}{|c|}{ Dieta } & \multirow[b]{2}{*}{ Média } & \multirow[b]{2}{*}{$\mathrm{CV}^{2}$} \\
\hline & $\begin{array}{l}\text { Silagem de } \\
\text { milheto }\end{array}$ & $\begin{array}{l}\text { Silagem de } \\
\text { mucilagem }\end{array}$ & $\begin{array}{c}\text { Silagem de } \\
\text { mucilagem + pó }\end{array}$ & $\begin{array}{c}\text { Feno de } \\
\text { mucilagem }\end{array}$ & & \\
\hline \multicolumn{7}{|l|}{ Consumo MS } \\
\hline g/dia & 799,9 & 938,7 & 1097,9 & 1116,2 & 988,2 & 21,2 \\
\hline$\% \mathrm{PC}$ & 2,5 & 2,7 & 2,8 & 3,0 & 2,7 & 11,9 \\
\hline $\mathrm{g} / \mathrm{kg}^{0,75}$ & 59,3 & 66,0 & 70,6 & 75,2 & 67,8 & 13,5 \\
\hline \multicolumn{7}{|l|}{ Consumo MO } \\
\hline g/dia & 750,1 & 864,8 & 1009,0 & 1034,9 & 914,7 & 21,1 \\
\hline$\% \mathrm{PC}$ & 2,3 & 2,5 & 2,6 & 2,8 & 2,5 & 11,8 \\
\hline $\mathrm{g} / \mathrm{kg}^{0,75}$ & 55,6 & 60,7 & 64,9 & 69,7 & 62,7 & 13,5 \\
\hline \multicolumn{7}{|l|}{ Consumo PB } \\
\hline g/dia & 121,8 & 139,8 & 168,1 & 167,4 & 149,3 & 21,2 \\
\hline$\% \mathrm{PC}$ & 0,3 & 0,4 & 0,4 & 0,4 & 0,4 & 11,7 \\
\hline $\mathrm{g} / \mathrm{kg}^{0,75}$ & 9,0 & 9,8 & 10,8 & 11,2 & 10,2 & 13,5 \\
\hline \multicolumn{7}{|l|}{ Consumo FDN } \\
\hline $\mathrm{g} / \mathrm{dia}$ & 284,8 & 289,6 & 339,6 & 336,3 & 312,6 & 22,2 \\
\hline$\% \mathrm{PC}$ & 0,9 & 0,8 & 0,9 & 0,9 & 0,9 & 12,8 \\
\hline $\mathrm{g} / \mathrm{kg}^{0,75}$ & 21,1 & 20,2 & 21,8 & 22,6 & 21,4 & 14,5 \\
\hline \multicolumn{7}{|l|}{ Consumo FDA } \\
\hline $\mathrm{g} / \mathrm{dia}$ & 137,7 & 155,7 & 181,4 & 170,4 & 161,3 & 22,7 \\
\hline$\% \mathrm{PC}$ & 0,4 & 0,4 & 0,5 & 0,5 & 0,5 & 12,7 \\
\hline $\mathrm{g} / \mathrm{kg}^{0,75}$ & 10,2 & $\begin{array}{l}0,4 \\
10,9\end{array}$ & 11,6 & 11,4 & 11,0 & 14,6 \\
\hline \multicolumn{7}{|l|}{ Consumo $\mathrm{CHO}$} \\
\hline $\mathrm{g} / \mathrm{dia}$ & 599,1 & 690,4 & 801,5 & 828,3 & 729,8 & 21,0 \\
\hline$\% \mathrm{PC}$ & 1,8 & 2,0 & 2,0 & 2,2 & 2,0 & 11,8 \\
\hline $\mathrm{g} / \mathrm{kg}^{0,75}$ & $\begin{array}{l}1,0 \\
44,4\end{array}$ & 48,5 & 51,5 & 55,8 & 50,1 & 13,4 \\
\hline \multicolumn{7}{|l|}{ Consumo CNF } \\
\hline g/dia & 314,3 & 400,8 & 461,8 & 492,0 & 417,2 & 20,5 \\
\hline$\% \mathrm{PC}$ & 0,9 & 1,1 & 1,1 & 1,3 & 1,1 & 11,9 \\
\hline $\mathrm{g} / \mathrm{kg}^{0,75}$ & 23,3 & 28,2 & 29,7 & 33,1 & 28,6 & 13,3 \\
\hline \multicolumn{7}{|l|}{ Consumo EE } \\
\hline $\mathrm{g} / \mathrm{dia}$ & 29,1 & 34,6 & 39,3 & 39,0 & 35,5 & 22,6 \\
\hline$\% \mathrm{PC}$ & 0,1 & 0,1 & 0,1 & 0,1 & 0,1 & 13,0 \\
\hline $\mathrm{g} / \mathrm{kg}^{0,75}$ & 2,1 & 2,4 & 2,5 & 2,6 & 2,4 & 14,8 \\
\hline
\end{tabular}

${ }^{1} \mathrm{MS}$ - matéria seca; MO - matéria orgânica; PB - proteína bruta; FDN - fibra em detergente neutro; FDA - fibra em detergente ácido; $\mathrm{CHO}$ - carboidratos totais; $\mathrm{CNF}$ - carboidratos não fibrosos; $\mathrm{EE}$ - extrato etéreo.

${ }^{2} \mathrm{CV}$ - Coeficiente de Variação em \%.

Os teores mínimos de FDN e máximos de CNF são os fatores limitantes à inclusão de coprodutos do sisal na dieta de borregos em confinamento. Em dietas de confinamento, com relação concentrado:volumoso de 60:40, níveis superiores a $18,5 \%$ de coproduto do sisal (base seca) fazem com que os níveis mínimos de FDN e máximos de CNF sejam extrapolados, podendo gerar distúrbios metabólicos. Esse fato também pode ser observado em dietas à base de palma forrageira, porque, apesar de esse alimento apresentar percentuais de FDN que variam de 26,1 a 35,8 (Wanderley et al., 2002), verifica-se a ocorrência de diarreias e perda de peso em ovinos alimentados exclusivamente com a palma. Bispo et al. (2007) observaram que o uso de até
$56,0 \%$ de palma forrageira em substituição ao feno de capim-elefante aumenta a ingestão, melhora o aproveitamento dos nutrientes e não ocasiona distúrbios metabólicos, em dietas para ovinos. No entanto, Veras et al. (2005), ao substituírem o milho por farelo de palma forrageira na alimentação de ovinos em crescimento, observaram que a adição do farelo de palma às dietas não alterou o consumo de matéria seca, porém diminuiu o consumo de energia e o ganho de peso.

As médias e os coeficientes de variação dos pesos iniciais e finais, ganho de peso médio diário, ganho de peso total e conversão alimentar encontram-se na Tab. 5. 
Tabela 5. Desempenho de ovinos alimentados com coprodutos do desfibramento do sisal

\begin{tabular}{|c|c|c|c|c|c|c|}
\hline \multirow[b]{2}{*}{ Variável $^{1}$} & \multicolumn{4}{|c|}{ Dietas } & \multirow[b]{2}{*}{ Média } & \multirow[b]{2}{*}{$\mathrm{CV}^{2}$} \\
\hline & $\begin{array}{l}\text { Silagem de } \\
\text { milheto }\end{array}$ & $\begin{array}{l}\text { Silagem de } \\
\text { mucilagem }\end{array}$ & $\begin{array}{c}\text { Silagem de } \\
\text { mucilagem + pó }\end{array}$ & $\begin{array}{c}\text { Feno de } \\
\text { mucilagem }\end{array}$ & & \\
\hline PI & 23,4 & 28,1 & 29,8 & 28,7 & 27,5 & - \\
\hline $\mathrm{PF}$ & 34,8 & 39,6 & 44,2 & 40,8 & 39,9 & - \\
\hline GPT (kg) & 11,4 & 11,5 & 14,4 & 12,1 & 12,3 & 20,4 \\
\hline GPD (g) & 181,8 & 183,6 & 229,0 & 191,3 & 196,4 & 20,4 \\
\hline $\mathrm{CA}$ & 4,5 & 6,1 & 4,0 & 6,1 & 5,2 & 41,7 \\
\hline
\end{tabular}

O ganho de peso diário médio não foi influenciado $(\mathrm{P}>0,05)$ pelas dietas. A similaridade do ganho de peso médio diário apresentado pelos animais submetidos às dietas pode ser atribuída ao consumo de MS semelhante entre as dietas. De acordo com Van Soest (1994), o consumo relaciona-se diretamente com o aporte de nutrientes e o atendimento das exigências nutricionais dos animais, sendo considerada a principal variável determinante do desempenho animal. Os ganhos de peso diários variaram de 181,8 a $229,0 \mathrm{~g}$ ( $\mathrm{P}>0,05)$, e o valor médio foi de 196,4g/dia.

Rodriguez et al. (1985) ao estudarem a adição de coproduto de sisal na dieta de ovinos das raças Pelibuey e Black Belly verificaram ganhos de peso diários que variaram de 70 a $81 \mathrm{~g} /$ animal/dia, valores abaixo dos encontrados neste ensaio. Estes autores observaram ainda taxas de conversão alimentar entre 8,2 e 9,4. Estes dados são próximos aos obtidos por Herrera et al. (1981), que reportaram 11,7 de conversão alimentar. Já Gebremariam e Machin (2008) relataram conversão alimentar variando de 17,0 a 21,0 . Tais resultados de conversão alimentar são superiores aos obtidos neste ensaio, que variaram de 4,0 a 6,1 .

Os resultados do presente estudo indicam o potencial de utilização do coproduto do sisal como ingrediente na composição de dietas para ruminantes no semiárido brasileiro. $\mathrm{O}$ melhor desempenho observado neste trabalho pode ser atribuído à melhor sincronização de proteína:energia, que afeta a conversão alimentar dos animais (Zundt et al., 2002) e ao melhor valor nutritivo dos coprodutos associados ao concentrado utilizados na pesquisa. Os resultados são justificados, ainda, pela semelhança dos consumos de alimentos, composição nutricional e digestibilidade das dietas.

Ressalta-se que a similaridade entre tratamentos acerca do ganho de peso diário proporcionou semelhanças entre os tratamentos quanto aos ganhos de pesos totais no período e, consequentemente, pesos corporais finais dos animais.

Nos resultados apresentados na Tab. 6, referentes à avaliação econômica das dietas experimentais contendo coprodutos do desfibramento do sisal (Tab. 6), o custo da dieta variou de 0,43 a 0,46 $\mathrm{R} \$ / \mathrm{kg}$ de MS, o que, associado ao CMS/cab/dia $(\mathrm{kg})$, gerou o custo da dieta, que variou de 0,37 a $0,50 \mathrm{R} \$ / \mathrm{cab} / \mathrm{dia}$.

A diferença entre os preços das dietas atingiu $5,4 \%$, referente ao valor máximo (dieta a base de feno de mucilagem) e ao mínimo (dieta à base de silagem de mucilagem). A margem líquida variou de 0,92 a 1,64 $\mathrm{R} \$ / \mathrm{kg}$, sendo observada influência do consumo de matéria seca aliada ao custo da dieta, na variável margem líquida. A melhor margem líquida foi obtida pelos animais do tratamento com silagem de mucilagem mais pó de batedeira, indicando que a inclusão de coprodutos do sisal pode aumentar a rentabilidade da atividade pecuária nas regiões onde existe a produção de sisal. É importante ressaltar que não houve influência dos custos fixos e operacionais relativos à produção ovina, pois estes foram computados no valor do custo da dieta. 
Tabela 6. Análise econômica das dietas experimentais em relação ao ganho de carcaça de cordeiros alimentados com coprodutos do desfibramento do sisal

\begin{tabular}{|c|c|c|c|c|}
\hline & \multicolumn{4}{|c|}{ Dieta } \\
\hline Ingrediente $^{1}$ & $\begin{array}{l}\text { Silagem de } \\
\text { milheto }\end{array}$ & $\begin{array}{l}\text { Silagem de } \\
\text { mucilagem }\end{array}$ & $\begin{array}{c}\text { Silagem de } \\
\text { mucilagem + pó }\end{array}$ & $\begin{array}{l}\text { Feno de } \\
\text { mucilagem }\end{array}$ \\
\hline Custo da dieta, $\mathrm{R} \$ / \mathrm{kg}$ de $\mathrm{MS}$ & 0,46 & 0,43 & 0,43 & 0,44 \\
\hline Consumo de MS (CMS), kg/dia & 0,79 & 0,93 & 1,09 & 1,11 \\
\hline Custo da dieta, $\mathrm{R} \$ / \mathrm{cab} / \mathrm{dia}$ & 0,37 & 0,41 & 0,47 & 0,50 \\
\hline $\begin{array}{l}\text { Ganho de peso médio (GPM, } \\
\mathrm{kg} / \mathrm{cab} / \mathrm{dia}\end{array}$ & 0,18 & 0,18 & 0,22 & 0,19 \\
\hline Custo da dieta, $\mathrm{R} \$ / \mathrm{kg}$ de GPM & 0,08 & 0,08 & 0,10 & 0,09 \\
\hline Margem líquida ${ }^{2}, \mathrm{R} \$ / \mathrm{kg}$ & 1,45 & 1,22 & 1,64 & 0,92 \\
\hline
\end{tabular}

${ }^{1}$ Os preços dos ingredientes referem-se a valores com frete incluso segundo o Sifreca com base na matéria seca do alimento; Silagem de Milheto: R\$0,20/kg; Fubá de Milho: R\$0,50/kg; Farelo de soja: R\$1,08/kg; Silagem de mucilagem: R\$0,05/kg; Feno de mucilagem: R\$0,10/kg; Pó de batedeira: R\$0,20/kg; Suplemento Mineral: $\mathrm{R} \$ 1,47 / \mathrm{kg}$; Ureia/Sulfato de amônio: $\mathrm{R} \$ 1,12 / \mathrm{kg}$.

${ }^{2}$ Margem líquida $=($ ganho de peso $\mathrm{x}$ preço do $\mathrm{kg}$ do animal vivo $(\mathrm{R} \$ / \mathrm{kg})-$ custo da dieta $(\mathrm{R} \$ / \mathrm{kg})) /$ ganho de peso do período $(\mathrm{kg})$. Considerou-se o preço recebido pelo kg de peso vivo pago por frigoríficos da região: $\mathrm{R} \$ 3,50 / \mathrm{kg}$.

\section{CONCLUSÕES}

Os coprodutos do sisal apresentam potencial para uso na alimentação de ovinos. A inserção de coprodutos de sisal em dietas balanceadas para ovinos confinados não altera o consumo dos principais nutrientes e frações fibrosas dos alimentos, e promove ganho de peso satisfatório. A substituição parcial da silagem de milheto pela silagem de mucilagem de sisal mais o pó da batedeira propicia melhor margem líquida, indicando a viabilidade técnica e a econômica de coprodutos do sisal na dieta para ovinos.

\section{REFERÊNCIAS BIBLIOGRÁFICAS}

ALLEN, M.S. Effects of diet on short-term regulation of feed intake by lactating dairy cattle. J. Dairy Sci., v.83, p.1598-1624, 2000.

BISPO, S.V.; FERREIRA, M.A.; VÉRAS, A.S.C. et al. Palma forrageira em substituição ao feno de capim-elefante. Efeito sobre consumo, digestibilidade e características de fermentação ruminal em ovinos. Rev. Bras. Zootec., v.36, p.1902-1909, 2007.

CENSO agropecuário - IBGE, 2007. Disponível em: <http://www.ibge.gov.br/>. Acessado em: 2 dez. 2009.

FORBES, J.M. Integration of regulatory signal controlling forage intake in ruminants. J. Anim. Sci., v.74, p.3029-3053, 1996.
GEBREMARIAM, D.Y.; MACHIN, D.H. Evaluation of sun dried sisal pulp (Agave sisalana Perrine) as feed for sheep in Eritrea. Livest. Res. Rural Devel., v.20, 2008. (On-line edition).

GUIMARÃES JR., R.; GONÇALVES, L.C.; MAURÍCIO, R.M. et al. Cinética de fermentação ruminal de silagens de milheto. Arq. Bras. Med. Vet. Zootec., v.60, p.1174-1180, 2008.

HERRERA, F.; FERREIRO, M.; ELLIOTT, R. et al. The effect of molasses supplements on voluntary feed intake, live weight gain and rumen function in bulls fed basal diets of ensiled sisal pulp. Trop. Anim. Prod., v.6, p.178-185 , 1981.

KOZLOSKI, G.V.; TREVISAN, L.M.; BONNECARRÈRE, L.M. et al. Níveis de fibra em detergente neutro na dieta de cordeiros: consumo, digestibilidade e fermentação ruminal. Arq. Bras. Med. Vet. Zootec., v.58, p.893-900, 2006.

MERTENS, D.R. Creating a system for meeting the fiber requirements of dairy cows. J. Dairy Sci., v.80, p.1463-1481, 1997.

NEGESSE, T.; MAKKAR, H.P.S.; BECKER, K. Nutritive value of some non-conventional feed resources of Ethiopia determined by chemical analyses and an in vitro gas method. Anim. Feed Sci. Tech., v.154, p.204-217, 2009.

NUTRIENT requirement of small ruminants. Washington, DC: National Research Council, 2007. 362p. 
PINOS-RODRÍGUEZ, J.M.; ZAMUDIO, M.; GONZÁLEZ, S.S. et al. Effects of maturity and ensiling of Agave salmiana on nutritional quality for lambs. Anim. Feed Sci.Tech., v.152, p.298306, 2009.

RODRIGUEZ, A.; RILEY, J.A.; THORPE, W. Animal performance and physiological disturbances in sheep fed diets based on ensiled sisal pulp (Agave fourcroydes): II) The effect of forage source and removal of short fibers. Trop. Anim. Prod., v.10, p.195-204, 1985.

STATISTICAL analysis system. User's guide SAS, versão 9. Cary, NC: SAS Institute, 2002.

SILVA， O.R.R.F.; CARVALHO, O.S.; MOREIRA, J.A.N. et al. Peneira rotativa CNPA, uma alternativa para o aproveitamento da mucilagem na alimentação animal. Campina Grande: EMBRAPA-CNPA, 1998. (EMBRAPACNPA. Circular Técnica, 27).

SILVA, D.J.; QUEIROZ, A.C. Análise de alimentos: métodos químicos e biológicos. 3.ed. Viçosa, MG, 2002. 235p.

SNIFFEN, C.J.; O'CONNOR, J.D.; VAN SOEST, P.J. et al. A net carbohydrate and protein system for evaluating cattle diets: II. Carbohydrate and protein availability. J. Anim. Sci., v.70, p.3562-3577, 1992.
TILLEY, J.A.; TERRY, A.R. A two-stage technique for in vitro digestion of forages crops. J. Br. Grass. Soc., v.18, p.104-111, 1963.

VALADARES FILHO, S.C.; MAGALHÃES, K.A.; ROCHA Jr., V.R. et al. Tabelas brasileiras de composição de alimentos para bovinos. CQBAL 2.0. Viçosa, MG, 2006. 297p.

VAN SOEST, P.J.; ROBERTSON, J.B.; LEWIS, B.A. Methods for dietary fiber neutral detergent fiber, and non-starch polysaccharides in relation to animal nutrition. J. Dairy Sci., v.74, p.35833597, 1991.

VAN SOEST, P.J. Nutritional ecology of ruminant. 2.ed. Ithaca: Cornell University, 1994. 476p.

VÉRAS, R.M.L.; FERREIRA, M.A.; CAVALCANTI, C.V.A. et al. Substituição do milho por farelo de palma forrageira em dietas de ovinos em crescimento. Desempenho. Rev. Bras. Zootec., v.34, p.249-256, 2005.

WANDERLEY, W.L.; FERREIRA, M.A.; ANDRADE, D.K.B. et al. Palma forrageira (Opuntia ficus indica Mill) em substituição à silagem de sorgo (Sorghum bicolor (L.) Moench) na alimentação de vacas leiteiras. Rev. Bras. Zootec, v.31, p.273-281, 2002.

ZUNDT, M.; MACEDO, F.A.F.; MARTINS, E.N. Desempenho de cordeiros alimentados com diferentes níveis proteicos. Rev. Bras. Zootec, v.31, p.1307-1314, 2002. 